\title{
Vaikų bronchoskopinio tyrimo
} indikacijos

\author{
Neringa Valatkaitė, doc. dr. Jolanta Kudzyte் \\ KMU Vaikų ligų klinika
}

Reikšminiai žodžiai: bronchoskopija, vaikai.

Santrauka. Bronchoskopija plačiai taikoma vaikų kvėpavimo organų ligoms diagnozuoti. Straipsnyje aptariamos vaikų bronchoskopijos indikacijos, pateikiama Paryžiaus Necker Enfants Malades ligoninëje ir KMU Vaikų ligų klinikoje atliktų bronchoskopijy lyginamoji analizè.

Bronchoskopija - tai tiesioginè viršutinių ir apatinių kvėpavimo takų apžiūra, kuri taikoma diagnozuojant ir gydant daugeli kvėpavimo organų ligų.

Bronchoskopijos pradžia laikomi 1897 m., kai Gustav Killian pritaike standųji bronchoskopą kvẻpavimo takams apžiūrèti. $1964 \mathrm{~m}$. Shigeto Ikeda išrado fibrooptini bronchoskopą. Vaikų bronchoskopijos pradininku laikomas Robert Wood, pirmąsias bronchoskopijas vaikams atlikęs $1978 \mathrm{~m}$. Nuo to laiko techninès galimybès pagerejo, buvo sukurti itin ploni fibrobronchoskopai, tinkami tirti net neišnešiotiems naujagimiams, pagerèjo diagnostikos sąlygos ir padaugejo bronchoskopijos indikaciju.

2003 m. Europos respiratologų draugija (ERS) išleido metodines rekomendacijas „Vaikų kvejpavimo taku tyrimas fibrobronchoskopu" (angl. Flexible endoscopy of pediatric airway), kuriose pateiktos pagrindinès vaiku fibrobronchoskopijos indikacijos, kontraindikacijos, paciento paruošimo tyrimui, slopinimo, instrumento dezinfekavimo metodikos [1].

Brochoskopija gali būti atliekama fibrobronchoskopu arba standžiuoju bronchoskopu - priklauso nuo tyrimo indikacijų, tyrejjo igūdžių ir techninių galimybių [2].

Fibrobronchoskopo dydis pasirenkamas pagal vaiko amžių: naujagimiams tirti naudojamas $2,2-2,8 \mathrm{~mm}$, kūdikiams - 2,8-3,6 mm, 1-8 metų vaikams - 3,6 mm, vyresniems $-4,9 \mathrm{~mm}$ skersmens fibrobronchoskopas. Laikomasi taisyklès, kad fibrobronchoskopo skersmuo turètų būti $2 \mathrm{~mm}$ mažesnis už vaiko gerklų spindị.

\section{INDIKACIJOS BRONCHOSKOPIJAI ATLIKTI}

Bronchoskopiją rekomenduojama atlikti, kai tikètina jos nauda viršija galimą riziką, o ji yra tuo metu tiksliausias ir informatyviausias diagnostikos metodas $[1,3]$. Spręsti, ar atlikti bronchoskopiją vaikui, reikia individualiai, apsvarsčius anamnezę, klinikinius požymius ir ankstesnių tyrimų rezultatus. Bronchoskopija gali būti atliekama diagnozuojant, gydant ligą arba norint paimti tyrimams kvèpavimo takų sekreto, bronchoalveolinio lavažo (BAL) skysčio ar biopsinès medžiagos (1 lentelè).

Vaikų bronchoskopinio tyrimo indikacijos kinta priklausomai nuo vaiko amžiaus. Bronchoskopijos metu vaiko kvėpavimo takuose nerasti patologinių pokyčiuc kartais irgi labai svarbu, pavyzdžiui, atmetant kvėpavimo takų svetimkūnį. Diagnostinę bronchoskopijos vertę padidina informacija, gauta ištyrus kvèpavimo takų sekretą, BAL ar biopsinę medžiagą.

Dažniausia indikacija atlikti fibrobronchoskopija (FBS) - viršutinių ar apatinių kvėpavimo takų obstrukcija [1]. Stridoras, paprastai rodantis viršutinių kvėpavimo takų obstrukciją, - dažna indikacija kūdikiams. Dažniausiai fibrobronchoskopas įkišamas pro nosị, todèl galima ịvertinti adenoidus, gerklas, gerklinę ryklès dalị, taip pat gerklų struktūrą ir funkciją ịkvèpimo ir iškvejpimo metu. Laringomaliacija yra dažniausia igimta gerklų anomalija ir dažniausia persistuojančio vaikų stridoro priežastis. Kitos gerklų anomalijos, sukeliančios stridorą yra šios: laringocelè, cista, gerklų 
1 lentelè. VAIKŲ BRONCHOSKOPINIO TYRIMO INDIKACIJOS [1]

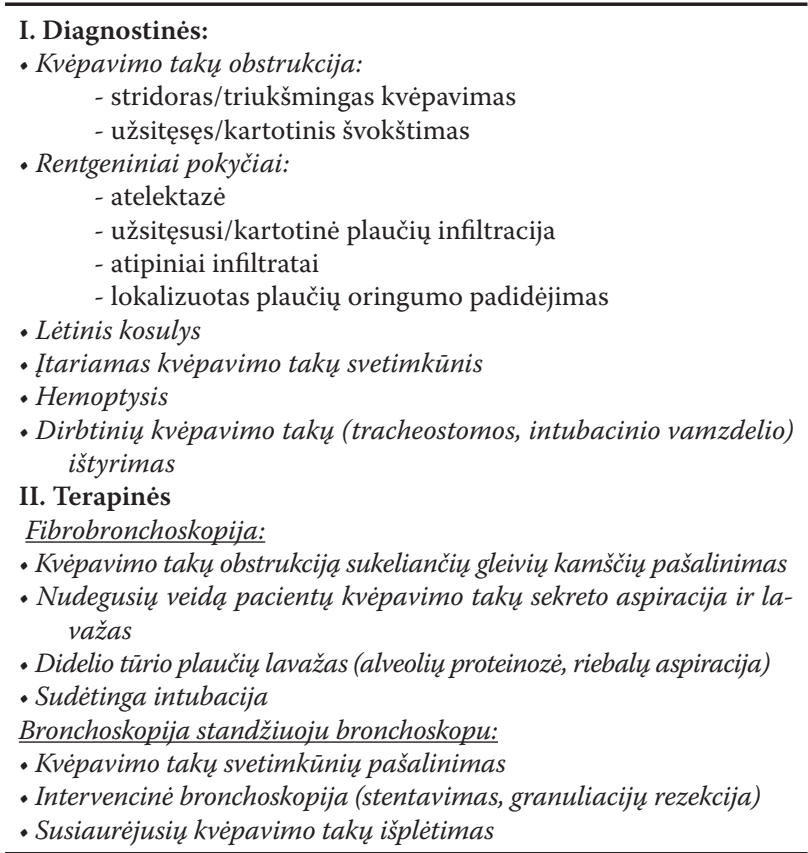

atrezija, laringotrachinè stenozé, gerklụ ir trachejos plyšys, hemangioma [4] . Kiekvienos FBS metu, jei imanoma, reikia stengtis ịvertinti tiek viršutinius, tiek ir apatinius kvėpavimo takus. Nors apatinių kvejpavimo takų endoskopija nèra būtina kiekvienam stridorą patiriančiam vaikui, bet ją reikètú atlikti tais atvejais, kai užkimęs balsas, $\mathrm{SpO}_{2}$ svyruoja ar kartojasi apnejos. Vyresniems vaikams stridoras būna daug rečiau, jam atsiradus, FBS yra būtina (išskyrus tuos atvejus, kai stridoras sąlygotas neseniai darytos intubacijos) [1].

Užsitęsęs/kartotinis švokštimas, kai neefektyvus gydymas bronchus plečiančiais ir uždegimą slopinančiais vaistais, yra viena pagrindinių klinikinių indikacijų atlikti FBS, dažniau kūdikiams ir mažiems vaikams. Švokštimas gali būti sąlygojamas igimtų anomalijų: pirminès tracheomaliacijos ir bronchomaliacijos, trachejjos stenozès, antrinès tracheomaliacijos ir bronchomaliacijos, tracheoezofaginès fistulès ar stemplès atrezijos, padidejusio kairiojo skilvelio ar igimtuc cistų [4]. D. E. Schellhase duomenimis, igimtų anomalijų rasta 57 proc. pacientų, esant pasikartojančiam užsitęsusiam švokštimui, be to, jos buvo dažnesnès kūdikiams iki 6 mèn. amžiaus [5]. Lokalizuotas monofoninis švokštimas gali būti esant svetimkūniui.

Ivairūs rentgeniniai pokyčiai - taip pat svarbi FBS indikacijų grupè. Kartotinès/užsitęsusios atelektazès, kartotinè pneumonija, užsitęsusi plaučių infiltracija gali būti sukeliamos laiku nediagnozuotų svetimkūnių, anatominių anomalijų, obstrukciją sukèlusių gleivių kamščių. Šiais atvejais taip pat labai svarbu atlikti BAL, siekiant atmesti intersticines plaučių ligas. Lokalizuotas plaučių oringumo padidejimas galimas dèl dalinès broncho obstrukcijos, sąlygotos svetimkūnio, išorinio broncho spaudimo ar lokalios bronchomaliacijos.
Lètinis kosulys, kai ịprastiniai tyrimai (krūtinės ląstos rentgenograma, spirograma, kraujo tyrimai) yra normalūs ir gydymas neefektyvus, taip pat yra indikacija atlikti FBS. Tokiu atveju reikia atmesti svetimkūnị ir igimtas anomalijas. Pastaruoju metu literatūroje pradètas vartoti terminas „užsitęsęs bakterinis bronchitas", kuriam būdinga daugiau nei 4 savaites trunkantis produktyvus kosulys, kartais su švokšti$\mathrm{mu}$, praeinantis nuo antibakterinio gydymo, ir nėra kitų specifinių kosulio priežasčių $[6,7]$. Tiriant vaikų lètinį kosulį, bakterinė kvėpavimo takų infekcija nustatyta 40 proc. atvejų [6]. Mažiems vaikams paimti kvėpavimo takų sekreto tyrimui dažnai pavyksta tik darant bronchoskopiją.

Ittariamas kvėpavimo takų svetimkūnis gali būti nustatomas FBS, tačiau jis šalinimas standžiuju bronchoskopu [8]. Hemoptysis - nedažna indikacija atlikti bronchoskopiją vaikams. Tačiau tais atvejais, kai hemoptysis yra sergant pneumonija, FBS indikuotina svetimkūniui, augliui ar kraujagyslių anomalijai atmesti [1]. Fibrobronchoskopu taip pat galima ištirti dirbtinių kvėpavimo takų (tracheostomos ar endotrachèjinio vamzdelio) padèti.

Terapinès bronchoskopijos pagrindinis tikslas kvėpavimo taku praeinamumo atkūrimas. Gleivių kamščiai ir kraujo krešuliai, lemiantys atelektazes, gali būti pašalinti FBS, nors kartais gali prireikti standžiojo bronchoskopo.

Galiausiai, FBS gali būti atliekama norint paimti endobronchinio bioptato, bronchų gleivinès nuobrūžų, transbronchinio bioptato, BAL ar pacientą intubuoti. Taip pat atliekant FBS galima instiliuoti vaistuc, pvz., surfaktanto ar DNazès [9].

\section{BRONCHOSKOPIJA VAIKŲ INTENSYVIOSIOS TERAPIJOS SKYRIUJE (VITS)}

Kvėpavimo sutrikimas gali būti pirminè priežastis, dèl kurios pacientas patenka i VITS, arba antrinė problema, kitų ligų, dèl kurių pacientas yra gydomas VITS, komplikacija. Vaikus, gydomus VITS, gali būti sudètinga bronchoskopuoti, nes jie dažniausiai esti ventiliuojami, hemodinamika nestabili ar sutrikęs kraujo krešejjimas. Vis dèlto FBS VITS yra saugi ir efektyvi procedūra, kai atliekama kvalifikuotai, ligonị tinkamai paruošus, nuslopinus ir reikiamai stebint.

FBS VITS dažniausiai atliekama, norint patikslinti su DPV susijusios pneumonijos sukèlèją, dèl kvèpavimo takų nudegimo, sudètingos intubacijos, kvėpavimo takų svetimkūnio ar kaip endobronchinis tualetas [10].

\section{BRONCHOSKOPIJA NAUJAGIMIŲ INTENSYVIOSIOS TERAPIJOS SKYRIUJE (NITS)}

Šiuolaikiniais 2,2 mm skersmens fibrobronchoskopais galima tirti net ir neišnešiotus naujagimius. Dažniausios indikacijos naujagimiams atlikti FBS yra strido- 
2 lentelè. BRONCHOSKOPIJOS INDIKACIJOS PARYŽIAUS NECKER ENFANTS MALADES LIGONINĖJE

\begin{tabular}{lc}
\hline Indikacijos & $\begin{array}{c}\text { Vaikų skaičius ir } \\
\text { procentinė dalis }\end{array}$ \\
\hline Kartotinė pneumonija & $294(22,1)$ \\
\hline Kartotinis obstrukcinis bronchitas & $204(15,4)$ \\
\hline Lėtinis produktyvus kosulys & $120(9,0)$ \\
\hline Intersticinis pneumonitas & $93(7,0)$ \\
\hline Užsitęsusi atelektazė & $74(5,6)$ \\
\hline Bronchektazės & $68(5,1)$ \\
\hline Kontrolinè bronchoskopija po gydymo & $65(4,9)$ \\
\hline Adenopatija & $51(3,8)$ \\
\hline Ūminė pneumonija & $48(3,6)$ \\
\hline Lokalizuotas plaučio dalies oringumo & $46(3,5)$ \\
\hline padidėjimas & \\
\hline Nekontroliuojama astma & $41(3,1)$ \\
\hline Lėtinis kosulys & $35(2,6)$ \\
\hline Stridoras & $33(2,5)$ \\
\hline Hemoptysis & $27(2,0)$ \\
\hline Užsitęsęs švokštimas & $26(2,0)$ \\
\hline Itariamas kvėpavimo takų svetimkūnis & $11(0,8)$ \\
\hline Kitos & $92(7,0)$ \\
\hline
\end{tabular}

ras, nesėkminga ekstubacija, persistuojanti atelektazè, nepaaiškinami cianozès priepuoliai, nepaaiškinamas kvépavimo sutrikimo sindromas, stridoras.

\section{KONTRAINDIKACIJOS BRONCHOSKOPIJAI ATLIKTI}

Robert Wood 1984 m. teigè: „Jei bronchoskopijos tikètina informacija ar gydomoji nauda esminè, kontraindikacijų bronchoskopijai atlikti nèra".

Santykinès kontraindikacijos gali būti plautinè hipertenzija, hipoksija, nekoreguoti kraujo krešèjimo sutrikimai [1].

\section{VAIKAMS ATLIKTŲ BRONCHOSKOPIJŲ PALYGINIMAS}

Paryžiaus Necker Enfants Malades ligoninèje 1997$2001 \mathrm{~m}$. atliktos 1328 fibrobronchoskopijos [11]. Ju indikacijos nurodytos 2 lenteleje. Vaikų pasiskirstymas pagal amžių matomas 1 paveiksle.

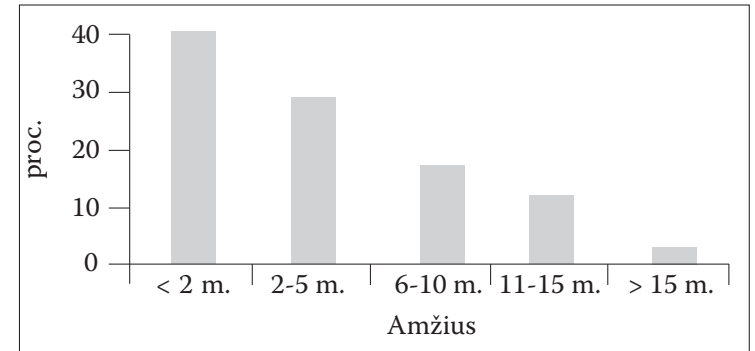

1 pav. VAIKŲ, KURIEMS ATLIKTA BRONCHOSKOPIJA, PASISKIRSTYMAS PAGAL AMŽIŲ PARYŽIAUS NECKER ENFANTS MALADES LIGONINĖJE
3 lentelè. BRONCHOSKOPIJOS INDIKACIJOS KMU VAIKU LIGU KLINIKOJE

\begin{tabular}{lc}
\hline Indikacijos & $\begin{array}{c}\text { Vaikų skaičius ir } \\
\text { procentinė dalis }\end{array}$ \\
\hline İtariamas kvėpavimo takų svetimkūnis & $109(15,6)$ \\
\hline Užsitęsęs švokštimas & $98(14)$ \\
\hline Pneumonija & $90(12,9)$ \\
\hline $\begin{array}{lc}\text { Itariama bronchektazinė liga, cistinė } \\
\text { fibrozė }\end{array}$ & $83(11,9)$ \\
\hline Stridoras & $61(8,7)$ \\
\hline Nekontroliuojama astma & $59(8,5)$ \\
\hline Lėtinis kosulys & $53(7,6)$ \\
\hline Intubacija FBS & $27(3,9)$ \\
\hline Rentgeninės „anomalijos“ & $27(3,9)$ \\
\hline Tracheostoma & $24(3,4)$ \\
\hline Užsitęsusi atelektazė & $23(3,3)$ \\
\hline Hemoptysis & $7(1)$ \\
\hline Kitos & $37(5,3)$ \\
\hline
\end{tabular}

KMU Vaikų ligu klinikoje 2003-2008 m. atliktos 698 bronchoskopijos. Dažniausios indikacijos nurodytos 3 lenteleje. Vaikų pasiskirstymas pagal amžių matomas 2 paveiksle.

KMU Vaikų ligų klinikoje vaikų bronchoskopinio tyrimo vyraujanti indikacija buvo įtariamas kvèpavimo takų svetimkūnis (15,6 proc.), o Paryžiaus Necker Enfants Malades ligoninejje svetimkūniai tebuvo indikacija daryti FBS tik 0,8 proc. atvejų. Užsitęsęs švokštimas, kartotinis obstrukcinis bronchitas - viena pagrindinių literatūroje nurodomų bronchoskopijos indikacijų, mūsų duomenimis, buvo antroje pagal dažnumą vietoje (14 proc.) po svetimkūnių, Paryžiuje taip pat antroje vietoje $(17,4$ proc.) po kartotinès pneumonijos. Kartotinė pneumonija buvo dažniausia bronchoskopijos indikacija (22,1 proc.) Paryžiaus Necker Enfants Malades ligoninèje, o mūsų klinikoje ji lèmè 12,9 proc. FBS ir buvo trečioje vietoje. Bronchoskopijų, atliekamu dèl lètinio kosulio, užsitęsusios atelektazès ir kraujo atkosėjimo buvo atliekama panašiai tiek Paryžiuje, tiek Kaune, atitinkamai dèl lètinio kosulio - 9,0 ir 7,6 proc., užsitęsusios atelektazès - 5,6 ir 3,3 proc., kraujo atkosejjimo -2 ir 1 proc.

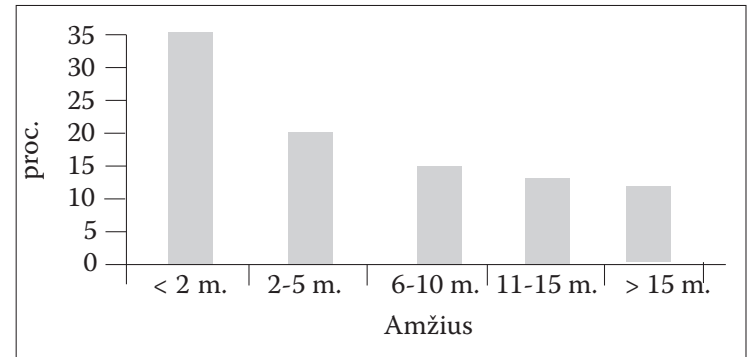

2 pav. VAIKŲ, KURIEMS ATLIKTA BRONCHOSKOPIJA, PASISKIRSTYMAS PAGAL AMŽIŲ KMU VAIKŲ LIGŲ KLINIKOJE 
Daugiausia bronchoskopuota jaunesnio amžiaus vaikų: iki 2 metų amžiaus - 40 proc. Paryžiaus Necker Enfants Malades ligonineje ir 35 proc. KMUK, iki 5 metu amžiaus atitinkamai 70 ir 56,2 proc. Didejant vaikų amžiui, atliekamų bronchoskopijų skaičius mažejo panašiai tiek Paryžiaus, tiek ir Kauno ligoninèje.

Daugumai vaikų, sergančių kvėpavimo sistemos ligomis, nereikia sudètingu tyrimų, o kai kada FBS yra labai vertinga diagnostinė ir gydomoji priemonè. Ji yra saugi ir efektyvi, jei atliekama kvalifikuotuc ir patyrusių specialistų, vaiką tinkamai paruošus ir nuslopinus. Tobulejanti technika atveria naujas FBS galimybes, o vaizdo aparatūra leidžia tyrimą dokumentuoti bei palengvina procedūros mokymąsi.

\section{LITERATŨRA}

1. F. Midulla, J. de Blic, A. Barbato, A. Bush et al. Flexible endoscopy of pediatric airways. ERS Task Force. Eur Respir J 2003; 22: 698-708.

2. T. Nikolai. Pediatric bronchoscopy. Pediatr pulmonol 2001; 31: 150-164.

3. Ian M. Balfour-Lynn, H. Spencer. Bronchoscopy - how and when? Paediatric respiratory reviews 2002; 3: 255-264.

4. L. D. Holinger. Congenital laryngeal anomalies. Pediatric Laryngology \& Bronchoesophagology. Philadelphia, Lippincott-Raven 1997; pp. 137-164.

5. D. E. Schellhase, D. D. Fawcett, G. E. Schutze et al. Clinical utility of flexible bronchoscopy and bronchoalveolar lavage in young children with reccurent wheezing. J Pediatr.1998 Feb; 132(2): 312-8.

6. J. M. Marchant, I. B. Masters, S. M. Taylor et al. Evaluation and outcome of young children with chronic cough. Chest 2006; 129: 1132-1141.

7. J. M. Marchant, I. B. Masters, S. M. Taylor et al. Utility of signs and symp-

\section{INDICATIONS FOR PEDIATRIC BRONCHOSCOPY}

NERINGA VALATKAITE, JOLANTA KUDZYTE

CLINIC OF CHILDREN DISEASES KAUNAS UNIVERSITY OF MEDICINE

Keywords: bronchoscopy, children.

Summary. Bronchoscopy is common used to diagnose pediatric respiratory diseases. In this article we analyse indications for pediatric bronchoscopy. Comparative analysis of indications for bronchoscopy in Necker Enfants Malades Hospital, Paris and Clinic of Children Diseases, Kaunas University Clinic is given in the article, as well.

\section{Būsimų renginių kalendorius}

\begin{tabular}{|c|c|c|}
\hline Data & Renginys & Vieta \\
\hline 2009-06-06-10 & $\begin{array}{l}\text { 28-asis EAACI (angl. European Academy of Allergy and } \\
\text { Clinical Immunology) kongresas }\end{array}$ & Varšuva, Lenkija \\
\hline 2009-06-11-15 & $\begin{array}{l}\text { FOCIS (angl. Federation of Clinical Immunology Societies) } \\
\text { metinè konferencija }\end{array}$ & San Franciskas, JAV \\
\hline 2009-06-17-20 & 10-asis tarptautinis plaučių vėžio kongresas & Kohala pakrantė, Havajai, JAV \\
\hline $2009-07-22-26$ & $\begin{array}{l}\text { Imunologijos mokslinè tarptautinė FIRN (angl. Frontiers in } \\
\text { Immunology Research Network) konferencija }\end{array}$ & Havajai, JAV \\
\hline 2009-07-31-08-04 & Pasaulinė plaučių vėžio konferencija & San Franciskas, JAV \\
\hline 2009-09-12-16 & ERS (angl. European Respiratory Society) metinis kongresas & Viena, Austrija \\
\hline 2009-09-25 & Kasmetinė LPAD rudens konferencija & Palanga, Lietuva \\
\hline 2009-09-22-25 & $\begin{array}{l}\text { INTERASTHMA (angl. International Association of Asthmology) } \\
\text { konferencija }\end{array}$ & Kanarų salos, Ispanija \\
\hline 2009-10-31-11-05 & $\begin{array}{l}\text { CHEST (angl. American College of Chest Physicians) metinè } \\
\text { konferencija }\end{array}$ & San Diegas, JAV \\
\hline 2009-12-03-07 & 40-oji jungtinė pasaulio plaučių ligų konferencija & Kankunas, Meksika \\
\hline $2009-12-06-10$ & 21-asis WAO (angl. World Allergy Organisation) kongresas & Buenos Aires, Argentina \\
\hline
\end{tabular}

